\title{
Hydrocarbon produced from upgrading rich phenolic compound bio-oil with low catalyst coking
}

\author{
Yi Wei ${ }^{1}$, Hanwu Lei ${ }^{*}, 2$, Lei Zhu' ${ }^{2}$,Xuesong Zhang ${ }^{2}$, Yupeng Liu $^{2}$, Gayatri Yadavalli ${ }^{2}$,
} Xiaolu Zhu' ${ }^{2}$, Moriko Qian ${ }^{2}$, Di Yan ${ }^{2}$

${ }^{1}$ Zhejiang Province Key Lab of Biofuel, Zhejiang University of Technology, Hangzhou, Zhejiang 310014, China

${ }^{2}$ Bioproducts, Sciences and Engineering Laboratory, Department of Biological Systems Engineering, Washington State University, Richland, Washington 99354-1671, United States, Telephone: 509-372-7628 Fax: 509-372-7690 E-mail:

hlei@wsu.edu

Abstract: Catalytic upgrading of raw bio-oil and liquid-liquid extracted bio-oil (high concentrated phenolic with trace acid and acetaldehyde) with methanol over ZSM-5 catalyst had been studied in this work. Temperature played vital function and leaded to increasing gas yield but less catalyst coking. It also changed both chemical distribution and selectivity on both gas and liquid products, with aromatic concentration increasing by $34.42 \%$. Temperature of $400{ }^{\circ} \mathrm{C}$ was selected as the optimized reaction conditions with liquid yield of $10.47 \mathrm{wt.} \%$ and $75.00 \%$ aromatic hydrocarbon in liquid product from 100g biomass, only with coke yield of 1.42 wt. \%. Phenolic-rich extracted bio-oil obtained higher aromatic hydrocarbon yield (7.3 wt.\% increased from $1.1 \mathrm{wt} . \%)$ and lower coke yield (1.42 wt.\% decrease from 15.79 wt.\%) than raw bio-oil. Catalyst regenerated from this type of feedstock also achieved higher activity and longer useable running times on aromatic yield compared to fresh catalyst. This result suggested that 
lignin derived phenolic and guaiacol compounds were not the only reason caused catalyst coking on ZSM-5 catalyst. Small high active molecules of acetic acid and acetaldehyde also acted as important precursors of catalyst coke formation.

Key word: aromatic, hydrocarbon, guaiacol, catalyst coking, ZSM-5

\section{Introduction}

Biomass has already been regarded as an attractive feedstock to replace petroleum, to produce renewable liquid fuels called bio-oil [1-3]. Pyrolysis is a thermochemical conversion process without oxygen, which can produce liquid bio-oil at $350-650{ }^{\circ} \mathrm{C}$ [4]. Due to its complex compounds, $35-40 \%$ oxygen content and high water content, it is essential to upgrade the bio-oil before direct use [5-7]. A considerable amount of research has been conducted on bio-oil upgrading with zeolite catalyst [8-11].

Although the results of these studies are sometimes contradictory, ZSM-5 is still recognized as the most promising zeolite catalyst [12]. According to prior research, the most difficult challenge in bio-oil upgrading is catalyst coking [13]. Catalyst coking occurs at all temperatures and presents a notable increase when increasing the temperature, especially above $400{ }^{\circ} \mathrm{C}$. Gayubo et al. [14] found formation of coke is an irreversible process [12]. The precursors of coking undergo polymerization and polycondensation on the catalytic surface and fill up the inner pores of zeolite catalyst, further contributing to inactivation of catalysts [10]. Several small molecules also repolymerize to form coke [28, 29]. Among all of the chemicals in bio-oils, oxygencontaining function groups, predominantly sugars, guaiacols, and furanic rings, are 
most likely to form coke because of their instability and deficiency in molar balance $[13,15,16]$. Obviously, acid sites in the pores play an important role in the coke deposition on the catalysts. Huang et al. [24] investigated that the acid sites acted as essential part of catalyst and donated protons to form hydrocarbon cation. The deprotonated basic framework of the zeolite offered potentials on cracking and aromatization, which promoted the catalytic deoxygenation, but resulted in coking.

Wang et al. [12] proposed that lignin derived phenolic compounds was easier to prone to coke and char than other two compounds in lignocellulosic biomass because of its complex structure and leaded to lower efficiency of carbon conversion. Nevertheless, Yu et al. [17] pointed out that a majority of lignin-derived compounds (such as coniferyl and syringyl) were too large for the pores of zeolites, as Zhang et al. [18] observed that the ZSM-5 had $0.53 \times 0.56 \mathrm{~nm}$ for straight channel and $0.51 \times 0.55 \mathrm{~nm}$ for sinusoidal channels. On the opposite, Carlson et al. [19] mentioned catalyst coke only could be formed on its external surface, because coke was unable to be accommodated within the narrow inner channels. Meanwhile, in our pre-studies on catalytic cracking and upgrading using pure phenol and guaiacol (2-methoxy phenol, 2-Methoxy-4-methylphenol) as model compounds, much less catalytic coke yield was found, than using pyrolysis oil. It is fully possible that significant interaction occurred between the other thermal-derived products such as acid, aldehyde, ester and phenolic compounds [20-23]. 
Many groups are currently focusing on seeking optimized catalysis conditions to reduce coke formation during the process $[3,9,11,12,25,26]$. Burning the coke at high temperature during the process is possible under certain conditions to reduce coking [25]. Co-feeding non-condensable gases into the reactor is also considered to have a great potential to minimize catalytic coking, by effectively reducing partial pressure, which leads to enhanced acidity and cracking activity of the catalyst to avoid catalytic coking $[11,26]$. Nevertheless, literature results indicated that burning, co-feeding with hydrogen and water, controlling reaction temperature, or reducing the acidity of the catalyst cannot drive down coking on the catalyst remarkably [25]. It is still a significant challenge to minimize coking at mild reaction conditions.

The phenolic compounds in bio-oil come not only from lignin, but also cellulose and hemicellulose. Bu et al [2] obtained a higher phenol yield from lignocellulosic biomass than model compound lignin under similar reaction conditions and furan ring compounds derived from cellulose and hemicellulose could also be converted into aromatic during catalytic pyrolysis on ZSM-5 catalyst. Our prior research has shown that liquid-liquid extraction using chloroform solvent on the water phase has had a significant effect in eliminating acid, alcohol and sugar compounds from the chloroform solvent phase [27]. In this work, we determined how ZSM-5 catalyst worked with a higher phenolic concentrated bio-oil extracted solution in a micro scale reactor. The self-design micro scale reactor pumped atomizing feedstock directly into high temperature systems, to avoid bio-oil coking during the feedstock heating period. 
Comparison had been placed between the catalyst coking condition and hydrocarbon product yield between different feedstock of raw bio-oil mixed with $50 \mathrm{wt}$ \% $\%$ methanol (RB) and phenolic-rich bio-oil fraction with $50 \mathrm{wt}$ \% methanol (PB). The objective was to give an overview of the reaction conditions for maximum hydrocarbon yield with low coking from bio-oil on ZSM-5 catalyst, and found the correlations between small active molecular such as aldehyde and catalyst coking.

\section{Experimental}

2.1 Catalyst and feedstock preparation

Methanol (Extra dry, SC, 99.8\%) was purchased from Fisher Scientific. Zeolite (CBV 5524G) was purchased from Zeolyst International. The ZSM-5 zeolite was activated with water, and then dried in an oven at $105^{\circ} \mathrm{C}$ for $12 \mathrm{~h}$. After water was removed from the mixture, the catalyst was calcined at $550{ }^{\circ} \mathrm{C}$ for $5 \mathrm{~h}$ before use. Catalyst regeneration was conducted by calcining in a furnace at $550{ }^{\circ} \mathrm{C}$ for $3 \mathrm{~h}$ and sealed storage before testing.

The RB was produced via microwave pyrolysis of Douglas fir pellet (cellulose $41 \%$, hemicellulose $21 \%$, lignin $32 \%$ ) at $450{ }^{\circ} \mathrm{C}$, for $25 \mathrm{~min}$ and a fixed microwave power input of 700W on a Sineo MAS-II batch microwave oven (Shanghai, China) with a rated power of $1000 \mathrm{~W}$. The rest solid after pyrolysis are weighted as the mas of solid product. RB was the liquid collected by cooling condenser and the rest was gas product. PB was obtained by a liquid-liquid extraction using RB as feedstock, and weighted 
113

114

after solvent distillation [27]. The bio-oil obtained from microwave pyrolysis was collected, following treated by the liquid-liquid extraction process (chloroform solvent), and the oil phase was stored in a sealed bottle in a freezer. Both RB and PB were mixed with 50 wt. \% ratio of methanol for dilution before use. The product yields and main components of these two types of feedstock are list in Table 1.

\subsection{Experimental method}

The catalytic upgrading process was conducted in a self-designed continuous fixed bed reactor, showed in Scheme 1. The reactor contained a vessel, a $10 \mathrm{~mL}$ container, a metal tube (inner diameter of $0.64 \mathrm{~cm}$ ) heated by a split heater, condensers and three valves. Before the experiment, the ZSM-5 catalyst was loaded in the metal tube in a ratio of 5 wt. \% to bio-oil feedstock (100g PB or RB). The catalyst was heated to the set temperature (from 350 to $450{ }^{\circ} \mathrm{C}$ ) with a heating rate of $1^{\circ} \mathrm{C} / \mathrm{s}$ in a nitrogen atmosphere. Each time, $10 \mathrm{~mL}$ of bio-oil was pumped into the hot catalyst tube controlled by the container and valves $\mathrm{A}, \mathrm{B}$. After 1 min retention time, valve $\mathrm{C}$ was opened and the mixture was separated via the condensers. The operation repeated ten times until all the $100 \mathrm{~g}$ of bio-oil feedstock took reaction with the catalyst. The non-condensable gas was immediately characterized after collection. After finish the experiment, the carrier gas was pumped into the tube to blow out the upgraded bio-oil. At the end of the experiment, the metal tube was removed from the system and the catalyst was collected for further characterization, regeneration and reuse. 


\subsection{Characterization methods}

Catalytic characterization was conducted before the experiments. The textural properties of ZSM-5 were measured by means of nitrogen adsorption-desorption (Micromeritics TriStar II 3020 Automatic Physisorption Analyzer). Temperature-programmed desorption (TPD) of ammonia with a Micromeritics AutoChem II 2920 Chemisorption Analyzer and Vapor Generator was used for determining the catalytic acidity.

The chemical composition of upgraded bio-oil was determined by Agilent GC/MS (GC-MS; GC, Agilent 7890A; MS, Agilent 5975C) with DB-5 capillary column. The GC was programmed by maintaining it at $45^{\circ} \mathrm{C}$ for $3 \mathrm{~min}$ followed by heating to 300 ${ }^{\circ} \mathrm{C}$ at a heating rate of $10{ }^{\circ} \mathrm{C} / \mathrm{min}$. The injection took place at $300{ }^{\circ} \mathrm{C}$, with sample injection size of $1 \mu \mathrm{L}$. The flow rate of the carrier gas (helium) was $0.6 \mathrm{~mL} / \mathrm{min}$. The ion source temperature was $230^{\circ} \mathrm{C}$ for the mass selective detector. The compounds were identified by comparing the spectral data with the NIST Mass Spectral library.

External standard method was applied for MS calibration before conducting the experiments, including Acetic acid, Acetaldehyde, Phenol, 2-methoxy-4-methyl(Guaiacol), Furfural, Benzene, Methylbenzene and Naphthalene. Water phase was tested with ethyl acetate extraction. The rest water phase was blended with methanol and tested by head-space method. 
157

158

159

160

161

162

163

164

165

166

167

168

169

170

171

172

173

174

Measurement of non-condensable gas required an INFICON 3000 Micro-GC

(INFICON Inc., Santa Clara, CA, USA) system with a thermal conductivity detector (TCD). The gaseous product was collected in a $0.6 \mathrm{~L}$ Tedlar gas bag. Offline analysis was done on the gas soon after the experiments, with standard gas calibration.

\section{Results and discussion}

3.1 Reactions of methanol on ZSM-5 catalyst

Independent experiments had been conducted on methanol to investigate the contribution of the small molecular on the catalyst. Results in Fig. 1 indicated methanol had strong potential to form alkane and aromatic via deoxygenation processes.

However, distinguished differences were observed on product yield and chemical distribution from the results of bio-oil. Methanol feedstock showed higher gas yield and lower catalyst coking than bio-oil feedstock during the process. The $\mathrm{C}-\mathrm{O}$ bonds in methanol were easy to break, resulted in synthesis unstable single carbon intermediate, which further form gaseous products, and the hydroxyl was removed with water synthesis simultaneously. The single carbon intermediate was also active to polymerize and formed multi-carbon product. The liquid from the process was separated into two phase: the upper organic phase contained hydrocarbon with neglectable water $(<0.1 \mathrm{wt}$. $\%$ ), while the lower water phase combined alcohol, trace acetic acid, ketones and 91.52 wt. \% water. In this research, the methanol blended with bio-oil worked on modifying the viscosity of bio-oil and reducing unwilling multi-rings aromatics in the final product, rather than achieving great contribution to hydrocarbon yield directly. 
3.2. Effect of temperature on product yield

Yield of liquid and gas from RB and PB [27] are shown in Fig. 2. Significant variations have been found between the feedstock. RB obtained lower liquid yield than PB across all the temperature ranges, and achieved its peak at $400{ }^{\circ} \mathrm{C}$ with liquid yield of $47.9 \mathrm{wt}$. \% (Fig. 2 A). In contrast, liquid yield of PB showed a diminishing trend accompanied with temperature increase, dropping from $67.57 \%$ to 63.9 wt. \%. Rising trend was elevated.

There are several explanations for this phenomenon. Zeolite catalyst is widely used as a high temperature deoxygenating catalyst. Higher temperature contributes to decomposition of large molecules to small gaseous ones, and leads to reduction on lower liquid yield from RB upgrading was not the same. As mentioned in the introduction, catalyst coking is the essential problem for catalytic upgrading, especially at low temperature (less than $400{ }^{\circ} \mathrm{C}$ ). Compared to simple categories of chemicals in PB, the raw one had complex constituents including acid, aldehyde and unpyrolyzed sugars. These small molecules with high activity have stronger affinity towards ZSM5 than heavy molecules of phenolic and guaiacol, at such temperature levels. High water content in RB also contributed to catalyst coking. Wang et al. [12] proposed that 
the volatile produced from this small molecule underwent oligomerization and dehydration at surface of ZSM-5 catalyst and inhibited feedstock diffusion into the pore of catalyst. Temperature played an important role on yield distribution in this study. $\mathrm{RB}$ required more restricted reaction condition of temperature due to its complex compounds in the feedstock.

\subsection{Effect of temperature on gas distribution}

The whole gaseous product from bio-oil upgrading of RB and PB, was investigated and is summarized in Fig. 3. Hydrogen, carbon oxides, methane and gaseous hydrocarbon were produced during the process. The total gaseous product yield increased with rising temperature. Carbon oxides are the major components in the product, and constituted at least $60 \% \mathrm{v} / \mathrm{v}$ of total mass across the temperature range. The carbon oxides increased from 12.68 to $22.62 \% \mathrm{v} / \mathrm{v}$ for RB, and 16.15 to $25.41 \% \mathrm{v} / \mathrm{v}$, respectively. Hydrogen also changed from 0.25 to $0.58 \% \mathrm{v} / \mathrm{v}$ relatively. On the other hand, methane was generated abundantly as other hydrocarbon yields reduced from 4.88 to $3.07 \% \mathrm{v} / \mathrm{v}$ in the experiment. Additionally, the composition of other hydrocarbons varied from small hydrocarbons such as ethane to long chain hydrocarbon such as propane and butane. This was because higher temperature promoted the activity of ZSM-5 for cracking heavy molecules into small ones, accompanied by reinforcement of gaseous product yield, especially for carbon oxides and methane. Unlike other gas, the propane and butane were derived from branch chains on aromatic rings. Higher temperature 
provided higher energy and afforded methane and ethane synthesis, which further resulted in reduction in other hydrocarbon yield.

Interestingly, two types of feedstock showed dramatic difference in the presence of same catalyst. For RB feedstock, more hydrogen, methane and hydrocarbon was generated from the process. Approximately $30 \%, 65 \%$, and $50 \%$ of these three types of gas were achieved with PB, separately. On the contrary, carbon oxides from catalytic cracking of RB were lower than ones from PB. In addition, PB favored carbon monoxide production rather than carbon dioxide, while RB tended to obtain carbon dioxide instead. Research has observed ratio of carbon monoxide to carbon dioxide for both types of feedstock. Experimental groups for PB achieved 1.28 on average, compared to RB groups which merely achieved 0.93 . The acid sites on ZSM-5 had a tendency to produce carbon monoxide rather than carbon dioxide during the catalytic cracking process [2]. Phenolic and guaiacol compounds primarily followed the decarbonylation pathway to form aromatic hydrocarbon and carbon monoxide. Wang et al. [12] indicated $\mathrm{CO}$ generation strongly correlated with aromatic production. It was concluded that catalyst used in PB retained higher activity than the one used in RB. Various chemicals in RB, either the higher water content or small molecules such as acid and aldehyde, could bring about deactivation of catalyst.

\subsection{Effect of temperature on liquid distribution}


The liquid product from the experiment is the most attractive because of its higher hydrocarbon yield and variety of valuable compounds (Fig. 4). The percentages given here refer to a specific category of total mole of chemicals in the liquid products. According to the results, ketones, hydrocarbons, phenols, guaiacol and furan compounds were the major products in catalytic cracking process. Refer to Fig. 4 A. Hydrocarbon was the target product in our research, which increased from 17.44 to $51.79 \%$ for $\mathrm{RB}$, and 63.76 to $77.47 \%$ for $\mathrm{PB}$, when temperature changed from 350 to $450{ }^{\circ} \mathrm{C}$. More phenolic compounds and hydrocarbons were also generated with rising temperature, while reduction on yields of guaiacol and furan compounds had been observed at same time, as shown in Fig. 4 B and C. Taking results from gaseous products into consideration, it is possible that carbon monoxide release is correlated with aromatic yield change. Higher temperature contributed to guaiacol and furan compounds transforming into aromatics, giving rise to aromatic product accumulation. Meanwhile, carbon monoxide was released by decarbonylation.

An Investigation was conducted on the chemical distribution of liquid from two types of feedstock. In contrast, PB feedstock achieved considerable hydrocarbon yield over $63.7 \%$ than RB on all temperature levels. Relatively, the "reactants" for decarbonylation, guaiacols and furan compounds, maintained less than $4.88 \%$ and $1.41 \%$ individually over $375^{\circ} \mathrm{C}$, in the liquid product of PB feedstock. On the other hand, more phenol was generated using RB feedstock. This indicates that more guaiacol and furan compounds underwent the catalytic cracking process, with close to 
complete deoxygenation for the PB feedstock. The low yield with RB feedstock was restricted by catalyst coking caused by complex constituents. Not only lower hydrocarbon yield, but also mass loss was found during the process. For example, close to $25 \%$ of carbon mass was lost at $350^{\circ} \mathrm{C}$ using $\mathrm{RB}$ as feedstock, while the value of $\mathrm{PB}$ feedstock was merely less than $10 \%$. The carbon transformed into coke via polymerization, which caused a barrier for guaiacol diffusion and further blocked the pores of ZSM-5. Although complex components in RB caused potential for catalyst coking, alkane hydrocarbon production was promoted. In comparison, PB feedstock after liquid-liquid extraction removed abundant small molecule from the mixture.

Since zeolites accelerate unsaturation of hydrocarbons or cyclic hydrocarbons, the guaiacols and furan compounds in PB could only transformed into polycyclic aromatics rather than alkanes. $11.83 \%$ alkanes were generated from the RB feedstock, but the value of PB was one-tenth. The total liquid product yield dropped with rising temperature, attributing to more active gaseous production instead of liquid hydrocarbon. It is therefore a challenge to optimize the catalytic cracking process, as the liquid yield and aromatic selectivity must be balanced.

Attention was paid to the aromatic distribution of the liquid product. The percentages given below refer to a specific category of total mole of aromatic hydrocarbon in the liquid products. Reports from prior research in our group declared high polyaromatic concentration had been generated on ZSM-5 catalyst [2]. RB feedstock followed the similar situation, which bicyclic aromatic and polyaromatic took up the first place of 
aromatic yield. However, in this study using PB feedstock, the carbon selectivity of monocyclic aromatic reached $61.65 \%$, with selectivity of bicyclic aromatic dramatically dropping to $37.48 \%$. Toluene (22.05\%), xylene (19.01\%) and benzene $(13.43 \%)$ were the main products in monocyclic aromatics, while naphthalene and its ramification (30.39\%) were the main bicyclic compounds. Bu et al. [2] found that the acetaldehyde, phenolic and guaiacol could be derived via lignin pyrolysis, which had a great tendency to form polyaromatics and coking compared to carbohydrates from cellulose and hemicellulose. Though PB had a high concentration accumulation from lignin derived products, it removed the acetic acid and acetaldehyde from the mixture. Therefore it is reasonable that acetal acid and acetaldehyde could be the precursor for catalytic coking. The methanol blended with PB also played an important role, as it minimized the polymerization on these guaiacol compounds themselves.

\subsection{Mass flow of RB and PB on hydrocarbon production}

An overall mass flow of biomass accounting for the hydrocarbon production based on this system was described in Scheme. 2. The input of fixed mass of Douglas fir pellet as well as output for all the upgraded oil was calculated. Generally, 100g dry biomass pellet (with water content around 8\%) was put into the pyrolysis systems and converted into $38 \mathrm{~g}$ of RB, 32g of syngas and around $30 \mathrm{~g}$ of char each time. In contrast, $13 \mathrm{~g}$ of PB was collected from the follow-up liquid-liquid extraction. Then both of PB and RB blended with 50 wt. $\%$ methanol. Nevertheless, $57 \mathrm{~g}$ of RB oil emulsion mixture could archive $27.3 \mathrm{~g}$ of liquid yield but merely $4.1 \mathrm{~g}$ of organics via ZSM-5 cracking, because 
of its high water content and complicated compounds, resulting in coke and water formation. After catalytic cracking, 1.1g of hydrocarbon was obtained from 100g of biomass via RB route. Conversely, $\mathrm{PB}$ mixture obtained better performance on hydrocarbon $(7.3 \mathrm{~g})$ and phenol $(1.5 \mathrm{~g})$ production. These products were immiscible with water and floated upon the water phase, which was not observed with RB . Compared with fast pyrolysis, microwave pyrolysis had a considerable phenol and guaiacol yield in bio-oil producing, while lower light molecular concentration.

Solvent extraction applied in the PB system simplified the categories of chemicals and concentrated guaiacol and phenolic compounds in the mixture, which certainly would contribute to reduce undesired process and precisely what the results indicated.

Besides, using RB demanded larger amount of methanol for blending and diluting, but in return caused more coke from the mixture. The solvent extraction treatment was indispensable since unstable properties of $\mathrm{RB}$ and in consequent reduced catalyst coke formation during the catalytic cracking.

\subsection{Catalyst coking and regeneration}

The properties of catalysts were listed in Table 2. According to the BET test, total surface area and micropore area significantly changed after the experiments. The micropore area of catalyst on both RB and PB were decreased from $341.7 \mathrm{~m} 2 / \mathrm{g}$ to $145.1 \mathrm{~m} 2 / \mathrm{g}$ and $265.4 \mathrm{~m} 2 / \mathrm{g}$, respectively. The pore volume also decreased duo to catalyst coking. The micropore area of RB and PB was decreased by $22.33 \%$ and $57.54 \%$, individually. Meanwhile, the volume of RB and PB also dropped by $45.83 \%$ 
and $36.67 \%$. It indicates that solid residue was formed mainly due to catalytic cracking. As per the mass balance, higher catalytic cracking efficiency equals less catalyst coking synergistically. The catalyst regenerated at $550{ }^{\circ} \mathrm{C}$ approximated to fresh ZSM-5 for both kinds of feedstock on its properties of catalysts.

Fig. 5 shows the results obtained by the regenerated catalyst on chemical distribution of product. The results illustrate that catalyst coking occurred during the process. The coking yield for RB was $28.02 \mathrm{wt}$ \% for the first time and approached to $50 \mathrm{wt}$. \% after 5 times reuse. At the same time, the hydrocarbon yields reduced from $40.12 \%$ to $11.88 \%$. Interesting phenomenon had been found on aromatic hydrocarbon yield on these reused catalysts, where polyaromatic was the main product rather than monocyclic aromatics, even for PB feedstock. Taking the properties of the catalyst into consideration, the catalyst coke reduced both area and size of micropore on ZSM-5, which led to high frequency for aromatic undergoing polymerization themselves, in another word, aromatics were polymerized by thermal way rather than catalytic processing. The results from the reused catalyst indicated these catalyst coke generated, not only restricted hydrocarbon production, but also caused the huge mass loss. The conclusion on PB strongly supported our thesis, that lower coking was generated, highly consistent with its admirable liquid yield, hydrocarbon selectivity and lower coking yield. The hydrocarbon yield from the PB feedstock reached $44.71 \%$ at the catalyst's 5th reusing. Furthermore, the coking yield of the catalyst used in PR after 5 times only got $20.65 \mathrm{wt} . \%$, which was even less than coking rate firstly used on RB 
353

354

355

feedstock. Although both types of feedstock had competitive performance after catalyst regeneration, PB feedstock had a high hydrocarbon selectivity and low coking yield.

\subsection{Influence on catalyst coking by high active small molecular}

In regards to coking formation, the key roles played by small active molecules should not be overlooked. The chemical constitution of catalyst coking mainly formed with high molecule weight of polyaromatic. As a result, dozens of reports on catalytic pyrolysis attributed deactivation of catalyst to lignin derived phenolic and guaiacol compounds, especially for those who used lignin as feedstock and observed severe coke situations. Although Carlson et al. [19] thought catalyst coke only formed on its external site, Yu et al [17] research on zeolite structure indicated inner active sites account for coke formation because of their overwhelming amounts compared with external sites. Nonetheless, seldom research had been conducted focusing on these small molecules. Acetic acid and acetaldehyde in the bio-oil had faster diffusion rate and small molecule size, which brought them much easier to fill in the pore and attached with acid sites of ZSM-5 than phenol and guaiacol. The carbonyl group in acid and aldehyde worked as extra sites for polymerization with guaiacol and phenol in limited space. These extra active sites further polymerized with other carbonyl group on guaiacol, expended out of zeolite's moderate pore and covered the micropore area. Pyrolysis on cellulose and hemicellulose compounds always produced high concentration of acetic acids and acetaldehydes, but quite few of aromatic rings compounds. In contrast, products from lignin pyrolysis were consisted of not only rich 
375 phenolic compounds, but also these small molecules from branches. That was the

376 reasonable explanation for high catalyst coking on lignin feedstock.

\section{Conclusion}

379 In this study, we had investigated the catalytic cracking process on RB and PB

380 feedstock over ZSM-5 catalyst. The temperature efficiency was utilized as the single factor for controlling the experiments. Products yields and characteristics of catalyst were treated as the main standard to measure the feedstock. PB represented distinguished performance on reducing catalyst coking and achieving $75 \mathrm{wt}$. \% on hydrocarbon yield. High reaction temperature contributed to less catalyst coking, but also caused reducible liquid yield, by moderately removed precursor of coke in gas phase. Catalyst reuse and regeneration process indicated over $70 \mathrm{wt} . \%$ hydrocarbon yield with less than 10 wt. \% coking was found on PB feedstock for the reuse catalyst. PB feedstock had admirable advantages over RB with simplified categories in feedstock, because small active molecules also contributed to catalyst coke formation of zeolite's moderate pore to attach the guaiacol molecular.

\section{ACKNOWLEDGMENT}

The study was supported in part by The Agriculture and Food Research Initiative of

(Award Number: 2015-67021-22911; Award Number: 2016-67021-24533), 
397 Washington State University Office of Commercialization, the Offices of the

398 President and Provost in conjunction with the Vice President of Research, the 399 Washington Research foundation, and Chinese Scholarship Council.

400 


\section{REFERENCES}

[1] Balat Mustafa, Balat Mehmet. Political, economic and environmental impacts of biomass-based hydrogen. Int. J. Hydrogen Energy 2009; 34: 3589-603.

[2] Bu Q, Lei H, Ren S, Wang L, Holladay J, Qin Zhang. Production of phenols and biofuels by catalytic microwave pyrolysis of lignocellulosic biomass. Bioresour. Technol. 2011; 102: 7004-7.

[3] Ma ZQ, Custodis V, Bokhoven JA. Selective deoxygenation of lignin during catalytic fast pyrolysis. Catal. Sci. Technol. 2014; 4: 766.

[4] Goyal HB, Seal D, Saxena RC. Bio-fuels from thermochemical conversion of renewable resources: A review. Renewable \& Sustainable Energy Reviews 2008; 12: 504-17.

[5] Mohan D, Pittman CU, Steele PH. Pyrolysis of Wood/Biomass for Bio-oil: A Critical Review. Energy Fuels, 2006; 20: 848.

[6] Elliot DC. Chemicals from biomass. Elsevier Inc., 2004, San Diego.

[7] Huber GW, Iborra S, Corma A. Synthesis of Transportation Fuels from Biomass: Chemistry, Catalysts, and Engineering. Chem. Rev. 2006; 106: 4044-498.

[8] Dickerson T, Soria J. Catalytic Fast Pyrolysis: A Review. Energies, 2013; 6: 514 38.

[9] Ausavasukhi A, Sooknoi T, Resasco DE. Catalytic deoxygenation of benzaldehyde over gallium-modified ZSM-5 zeolite. J. Catal, 2009; 268: 68-78.

[10] Mortensen PM, Grunwaldt JD, Jensen PA, Knudsen KG, Jensen AD. A review of catalytic upgrading of bio-oil to engine fuels. Appl. Catal. A, 2011; 407: 1-19.

[11] Zhu XL, Mallinson RG, Resasco DE. Role of transalkylation reactions in the conversion of anisole over HZSM-5. Appl. Catal. A, 2010; 379: 172-81.

[12] Wang KG, Kim KH, Brown RC. Catalytic pyrolysis of individual components of lignocellulosic biomass. Green Chem., 2014; 16: 727.

[13] Furimsky E, Massoth FE. Deactivation of hydroprocessing catalysts. Catal. Today, $1999 ; 52: 381-495$. 
[14] Gayubo AG, Aguayo AT, Atutxa A, Aguado R, Bilbao J. Transformation of Oxygenate Components of Biomass Pyrolysis Oil on a HZSM-5 Zeolite. I. Alcohols and Phenols. Ind Eng Chem Res, 2004; 43: 2610-18.

[15] Centeno A, Laurent E, Delmon B. Influence of the Support of CoMo Sulfide Catalysts and of the Addition of Potassium and Platinum on the Catalytic Performances for the Hydrodeoxygenation of Carbonyl, Carboxyl, and Guaiacol-Type Molecules. J. Catal., 1995; 154: 288-98.

[16] Mahfud FH, Ghijsen F, Heeres HJ. Hydrogenation of fast pyrolyis oil and model compounds in a two-phase aqueous organic system using homogeneous ruthenium catalysts. J. Mol. Catal A, 2007; 264: 227-36.

[17] Yu YQ, Li XY, Su L, Zhang Y, Wang YJ, Zhang HZ. The role of shape selectivity in catalytic fast pyrolysis of lignin with zeolite catalysts. Appl. Catal. A., 2012; 447-448: 115-23.

[18] Zhang B, Zhong ZP, Chen P, Ruan R. Microwave-assisted catalytic fast pyrolysis of biomass for bio-oil production using chemical vapor deposition modified HZSM-5 catalyst. Bioresour. Technol. 2015; 197: 79-84.

[19] Carlson TR, Cheng YT, Jae J, Huber GW. Production of green aromatics and olefins by catalytic fast pyrolysis of wood sawdust. Energy Environ. Sci., 2011; 4: $145-61$.

[20] Gutierrez A, Kaila RK, Honkela ML, Slioor R, Krause AI. Hydrodeoxygenation of guaiacol on noble metal catalysts. Catal. Today, 2009; 147: 239-46.

[21] Effendi A, Gerhauser H, Bridgwater AV. Production of renewable phenolic resins by thermochemical conversion of biomass: a review. Renew. Sus. Ener. Rev., 2008; 12: $2092-116$.

[22] Wildschut J, Melián-Cabrera I, Heeres HJ. Catalyst studies on the hydrotreatment of fast pyrolysis oil. Appl. Catal. B, 2010; 99, 1-2: 298-300.

[23] Zhang XH, Wang TJ, Ma LL, Zhang Q, Zhang TJ. Hydrotreatment of bio-oil over Ni-based catalyst. Bioresour. Technol., 2013; 127: 306-11. 
457 [24] Huang J, Long W, Agrawal PK, Jones CW. Effects of Acidity on the Conversion 458 of the Model Bio-oil Ketone Cyclopentanone on H-Y Zeolites. J. Physical Chemistry 459 C, 2009; 113: 16702-10.

460 [25] Gualda G, Kasztelan S. Coke Versus Metal Deactivation of Residue 461 Hydrodemetallization. Catalysts. J. Catal., 1996; 161: 319-37.

462 [26] Peralta MA, Sooknoi T, Danuthai T, Resasco DE. Deoxygenation of 463 benzaldehyde over CsNaX zeolites. J. Mol. Catal A, 2009; 312: 78-86.

464 [27] Wei Y, Lei H, Wang L, Zhu L, Zhang X, Liu Y, Chen S, Ahring BK. 465 Liquid-liquid extraction of biomass pyrolysis bio-oil. Energy and Fuels. 2014; 28: $466 \quad 1207-12$.

467 [28] Ibarra A, Veloso A, Bilbao J, Arandes J M, Castaño P. Dual coke deactivation 468 pathways during the catalytic cracking of raw bio-oil and vacuum gasoil in FCC 469 conditions. Appl, Catal. B, 2016; 182: 336-46.

470 [29] Guisnet M, Costa L, Ribeiro FR. Prevention of zeolite deactivation by coking. J 471 Mol. Catal A, 2009; 305, 1-2: 69-83.

472 473 
475 Table 1. Product yield and chemical distribution of RB and PB

\begin{tabular}{|c|c|c|c|}
\hline Product Distribution & Bio-oil (RB) & Gas & Solid \\
\hline Yield (Biomass 100g) $(\mathrm{g})$ & 38 & 32 & 30 \\
\hline After solvent extraction & Bio-oil (RB) & Extracted-oil (PB & Water-phase \\
\hline Yield(Biomass 100g) (g) & 38 & 13 & 25 \\
\hline Water Content (wt. \%) & 64.51 & 9.20 & 93.26 \\
\hline Chemicals (base on chemical mole) & $\mathrm{RB}(\%)$ & \multicolumn{2}{|c|}{ PB $(\%)$} \\
\hline Acids: & 3.48 & \multicolumn{2}{|c|}{0} \\
\hline Acetic acid & 3.01 & \multicolumn{2}{|c|}{---} \\
\hline Aldehyde/ketone & 9.41 & \multicolumn{2}{|c|}{3.34} \\
\hline Acetaldehyde & 7.96 & \multicolumn{2}{|c|}{0} \\
\hline 1,2-Cyclopentanedione, 3-methyl- & 1.07 & \multicolumn{2}{|c|}{1.86} \\
\hline Alcohols & 1.41 & \multicolumn{2}{|c|}{0.09} \\
\hline Phenol & 4.52 & \multicolumn{2}{|c|}{4.07} \\
\hline Guaiacols & 54.50 & \multicolumn{2}{|c|}{72.02} \\
\hline Phenol, 2-methoxy- & 8.86 & \multicolumn{2}{|c|}{10.36} \\
\hline Phenol, 2-methoxy-4-methyl- & 17.20 & \multicolumn{2}{|c|}{29.09} \\
\hline Phenol, 4-ethyl-2-methoxy- & 7.94 & \multicolumn{2}{|c|}{20.54} \\
\hline Furan ring compounds & 17.59 & \multicolumn{2}{|c|}{20.46} \\
\hline Furfural & 10.08 & \multicolumn{2}{|c|}{17.49} \\
\hline 2-Furancarboxaldehyde,5-methyl- & 2.86 & \multicolumn{2}{|c|}{0} \\
\hline Furan,tetrahydro-2,5-dimethoxy- & 0.53 & \multicolumn{2}{|c|}{0.13} \\
\hline 2-Furanmethanol & 3.36 & \multicolumn{2}{|c|}{0} \\
\hline Esters & 2.72 & \multicolumn{2}{|c|}{0} \\
\hline Sugars & 0.73 & \multicolumn{2}{|c|}{0} \\
\hline Total & 100.00 & \multicolumn{2}{|c|}{100.00} \\
\hline
\end{tabular}


Table 2. Physical and chemical properties of catalyst (Used catalyst based on $400{ }^{\circ} \mathrm{C}$ process)

\begin{tabular}{lcccccc|c}
\hline Catalyst property & Si/Al & $\begin{array}{c}\text { Acidity }(\mathrm{mmol} \\
\left.\mathrm{NH}_{3} / \mathrm{g}\right)\end{array}$ & $\begin{array}{c}\mathrm{S}_{\text {BET }} \\
\left(\mathrm{m}^{2} / \mathrm{g}\right)\end{array}$ & $\begin{array}{c}\mathrm{V}_{\text {Micro }} \\
\left(\mathrm{cm}^{3} / \mathrm{g}\right)\end{array}$ & $\begin{array}{c}\mathrm{S}_{\text {Micro }} \\
\left(\mathrm{m}^{2} / \mathrm{g}\right)\end{array}$ & $\begin{array}{c}\mathrm{V}_{\text {Total }} \\
\left(\mathrm{cm}^{3} / \mathrm{g}\right)\end{array}$ \\
\hline ZSM-5 Fresh & 50 & 0.17 & 415.8 & 0.12 & 341.7 & 0.40 \\
\hline Used (RB) & & & 214.1 & 0.07 & 145.1 & 0.23 \\
\hline Used (PB) & & & 325.5 & 0.08 & 265.4 & 0.28 \\
\hline Regenerated (RB) & & & 386.9 & 0.10 & 185.4 & 0.35 \\
\hline Regenerated (PB) & & & 400.5 & 0.11 & 325.4 & 0.39 \\
\hline
\end{tabular}

479

480 


\section{Figure captions}

482 Fig. 1 Reaction of methanol, RB and PB on 5 wt. $\%$ ZSM-5, at $450{ }^{\circ} \mathrm{C}$ : A. Products 483 yield (Water contents of liquids are listed in the brackets); B. Chemical distribution in 484 liquid product. ${ }^{\text {a }}$ The liquid product obtained by RB stayed in one mixture phase, and 485 the distribution stood for organics in RB.

486 Fig. 2 Fig. 2 Effect of reaction temperature on product yields for the catalytic upgrading 487 of RB and PB on 5 wt. \% ZSM-5: A. Liquid yield; B. Gas yield; C. Solid yield (catalyst 488 coke)

489 Fig. 3 Effect of reaction temperature on gas distribution for the catalytic upgrading on 5 490 wt. \% ZSM-5: A. RB; B. PB

491 Fig. 4 Effect of reaction temperature on liquid distribution for the catalytic upgrading 492 on 5 wt. \% ZSM-5: A. Hydrocarbon yield; B. RB; C. PB.

493 Fig. 5 Effect of catalyst regeneration on product distribution for the catalytic upgrading 494 on 5 wt. $\%$ ZSM-5, at $400{ }^{\circ} \mathrm{C}$ : A. 1 st (RB); B.5th (RB); C. Regenerated (RB); D. 1 st 495 (PB); E. 5th (PB); F. Regenerated (PB) 


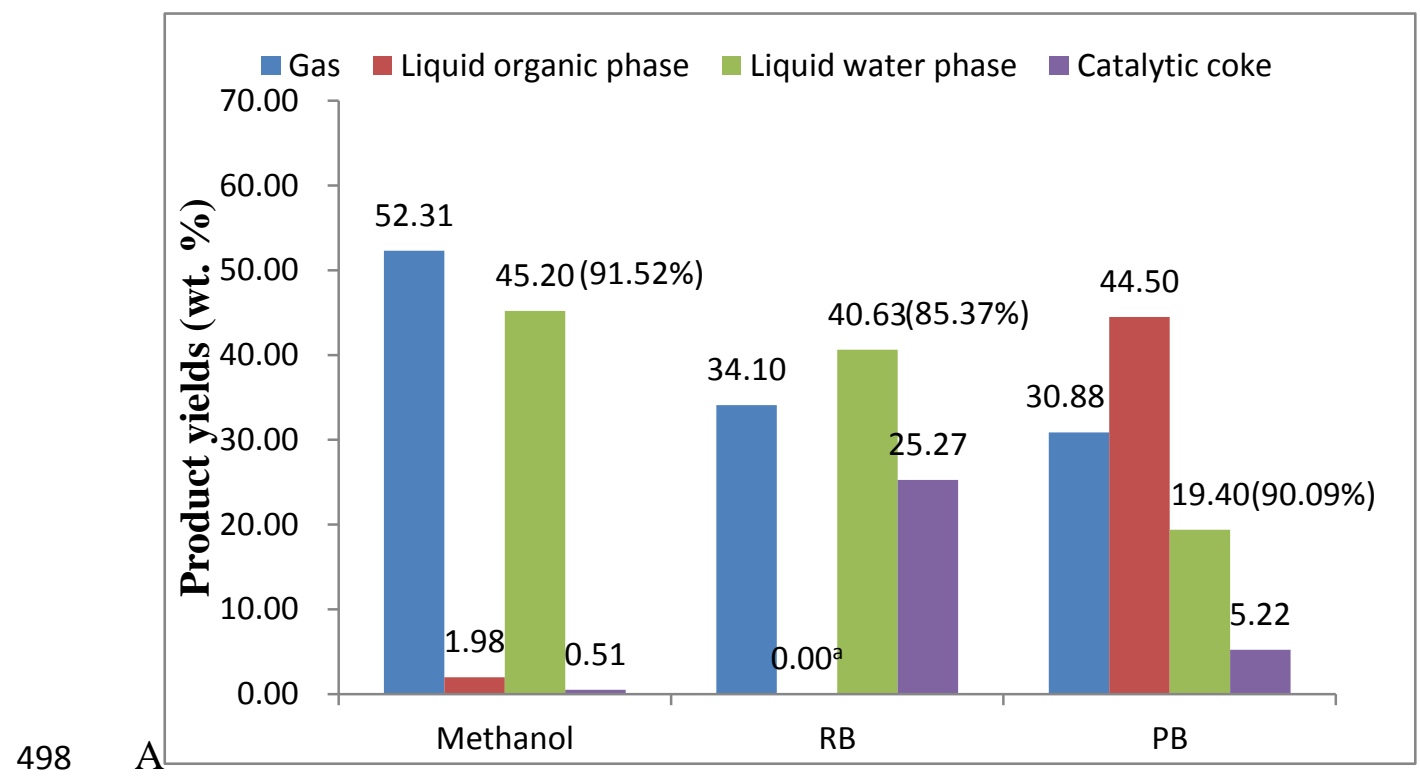

$499 \quad$ B

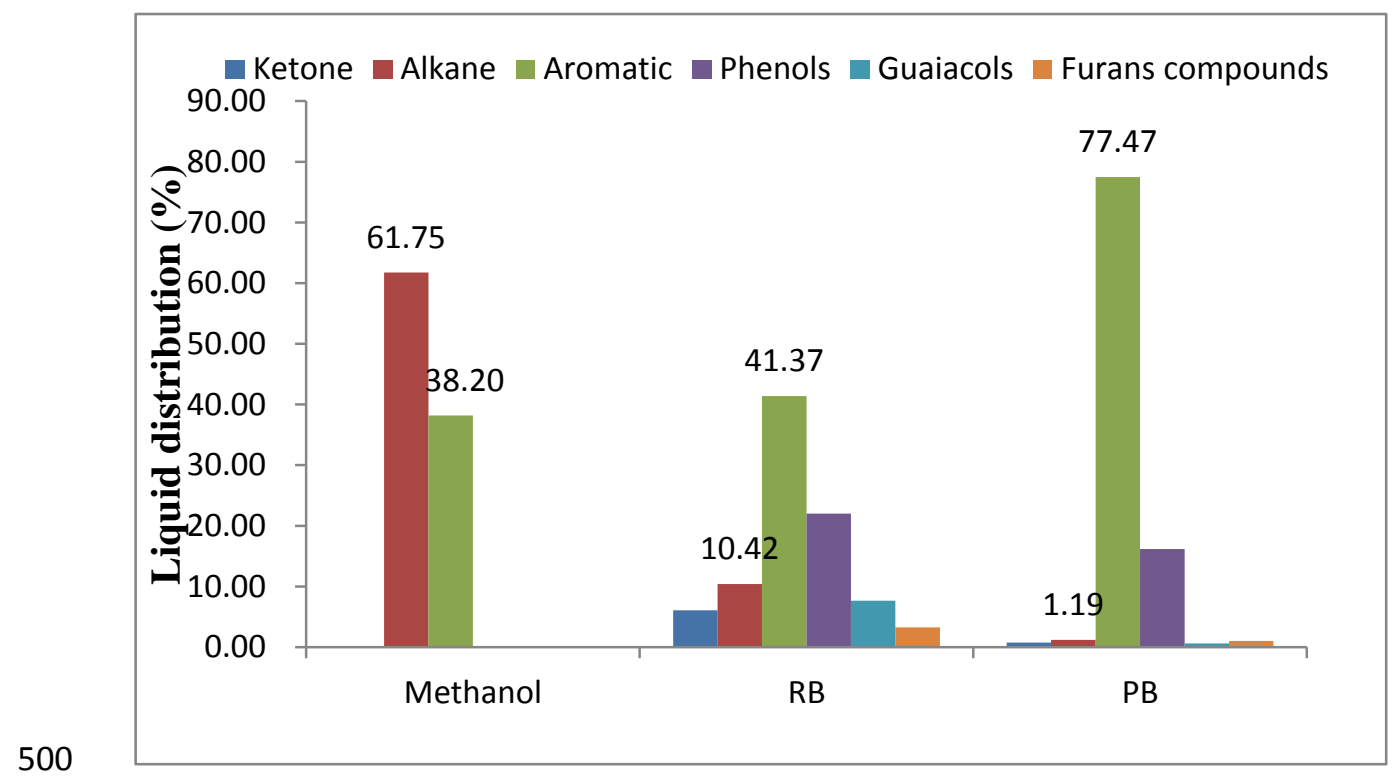

501 

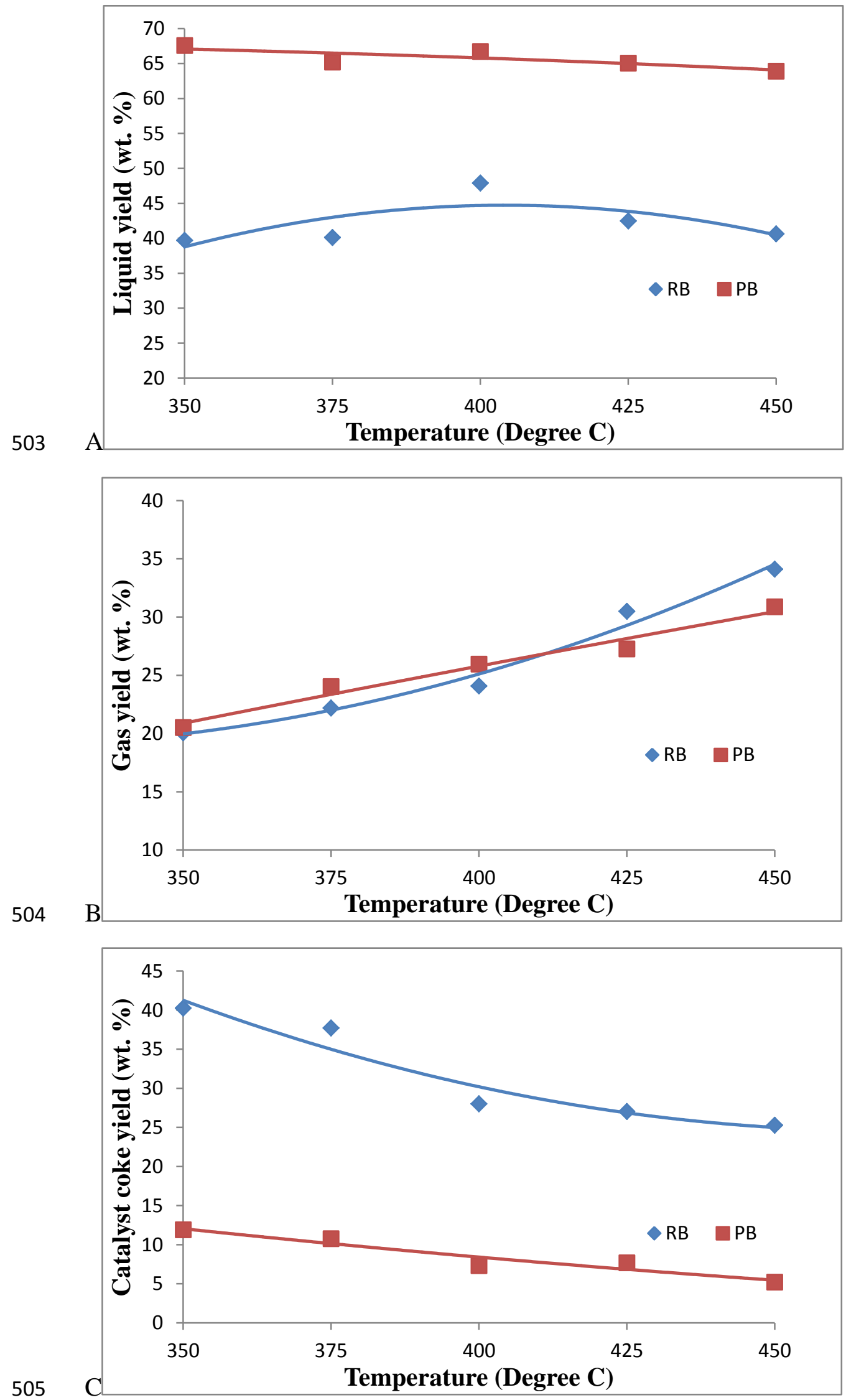
Fig. 3
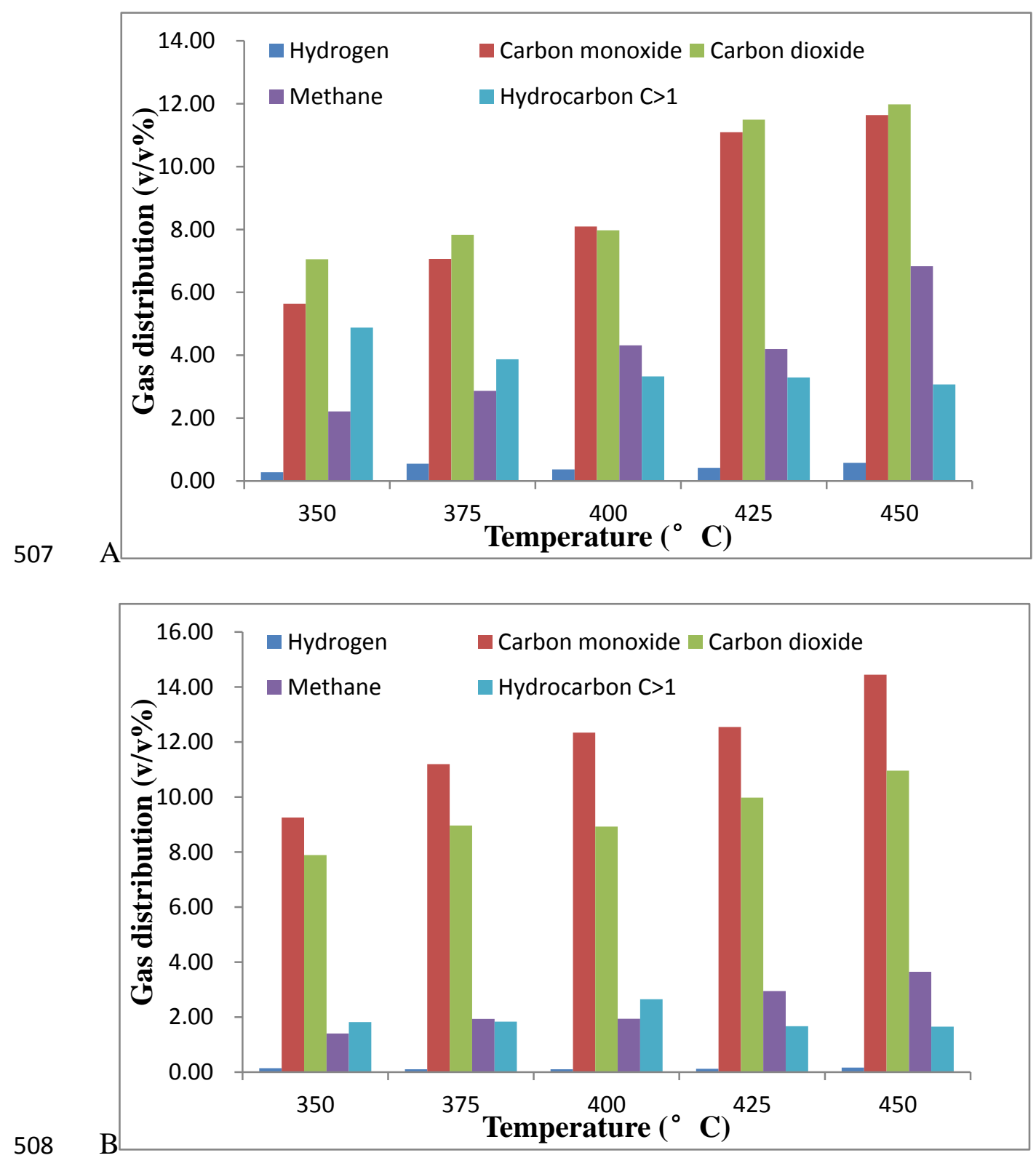

509 


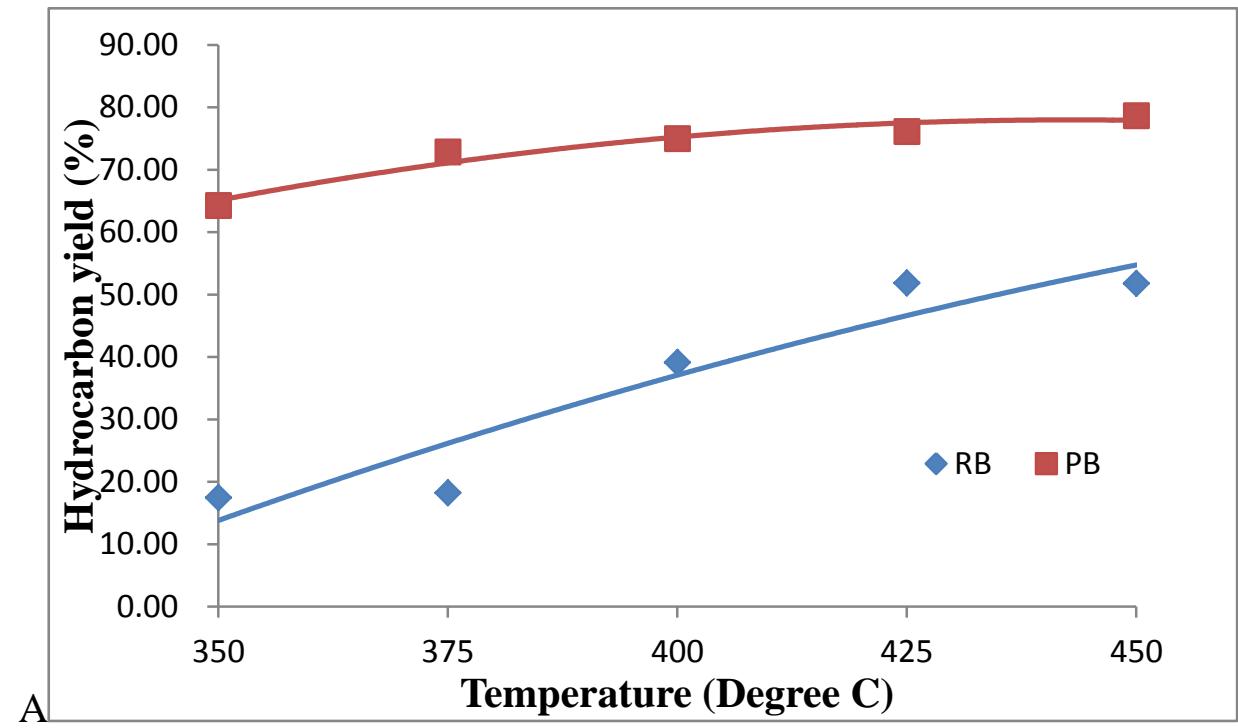

511
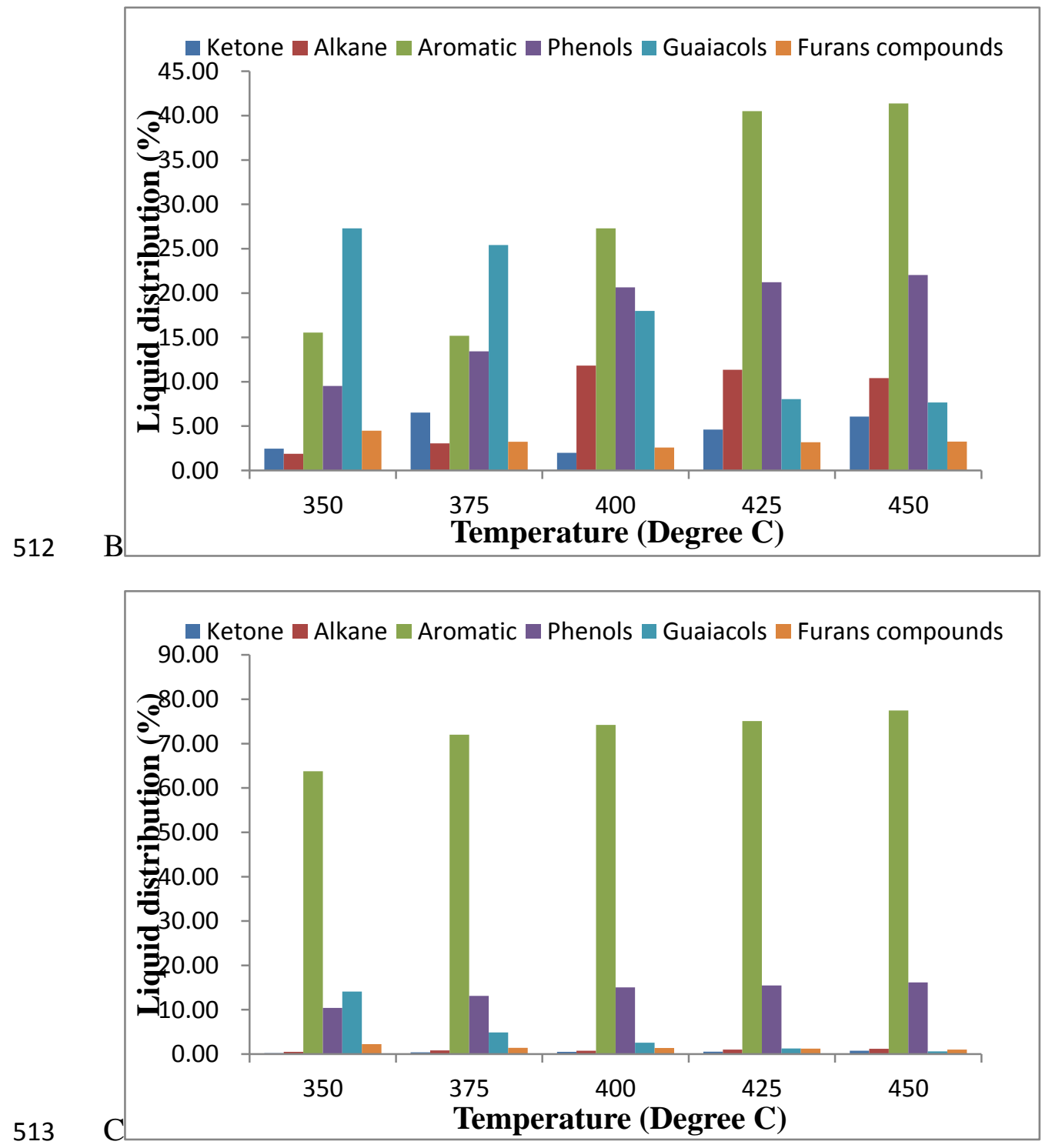
Fig. 5

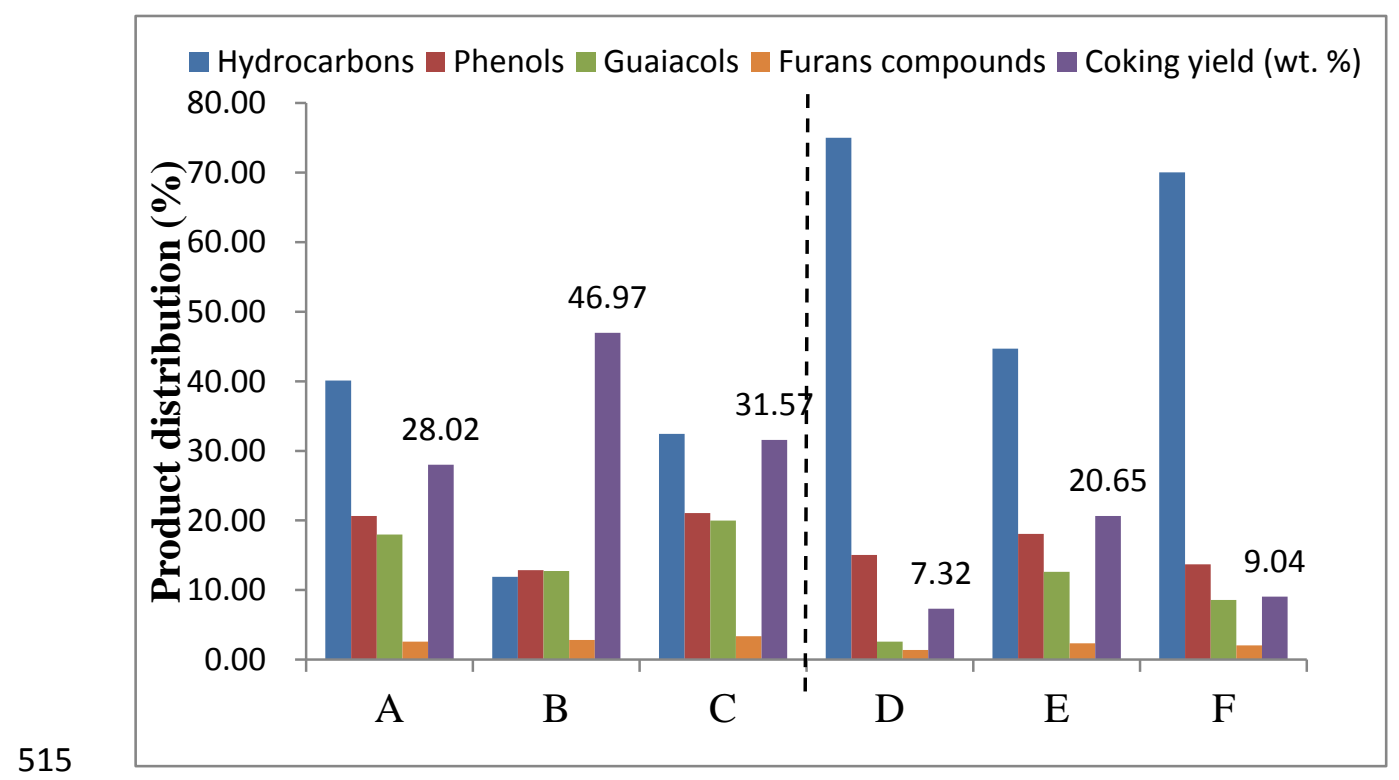


517 Scheme 1. The schematic diagram of the catalytic upgrading system

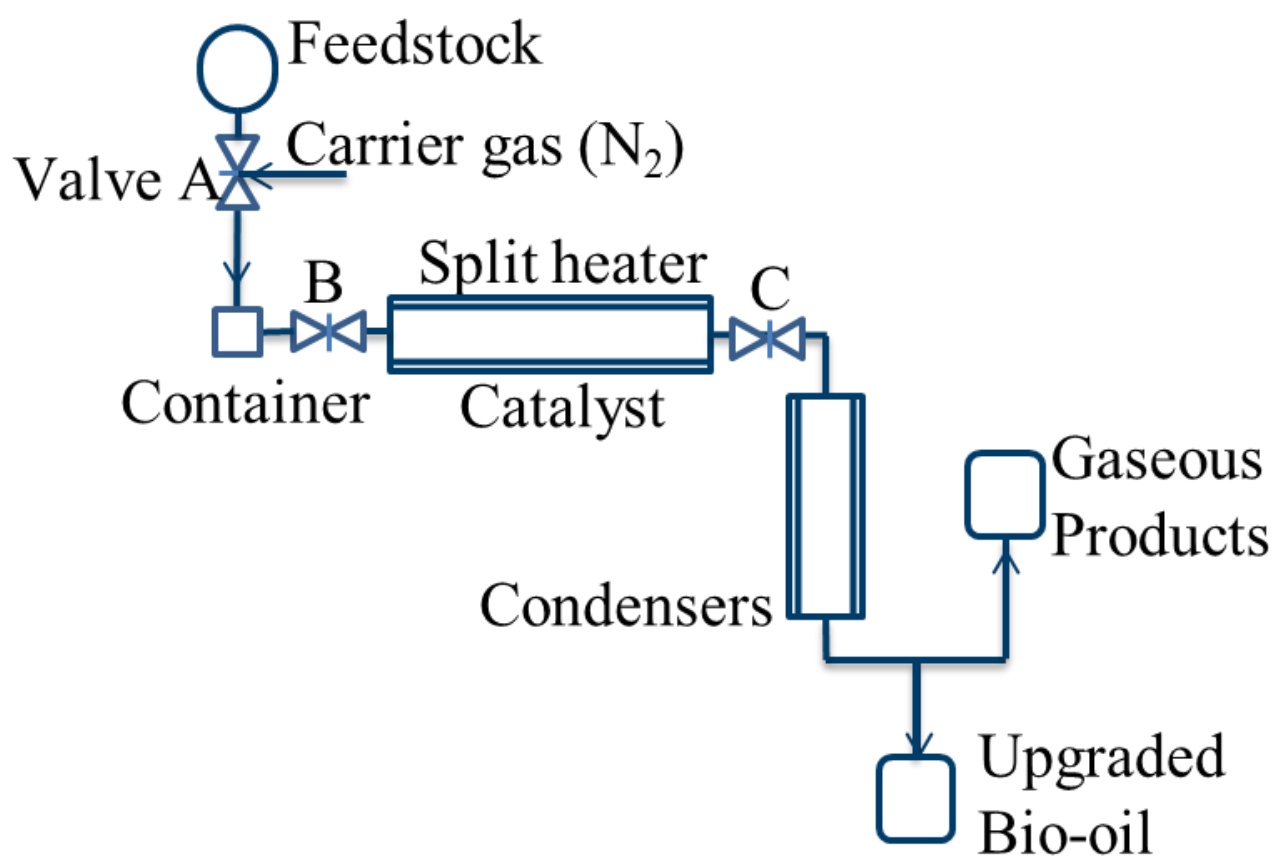


520 Scheme 2 . The mass flow of the catalytic upgrading system at $400{ }^{\circ} \mathrm{C}$ (the water content

521 of liquids are shown in the brackets)

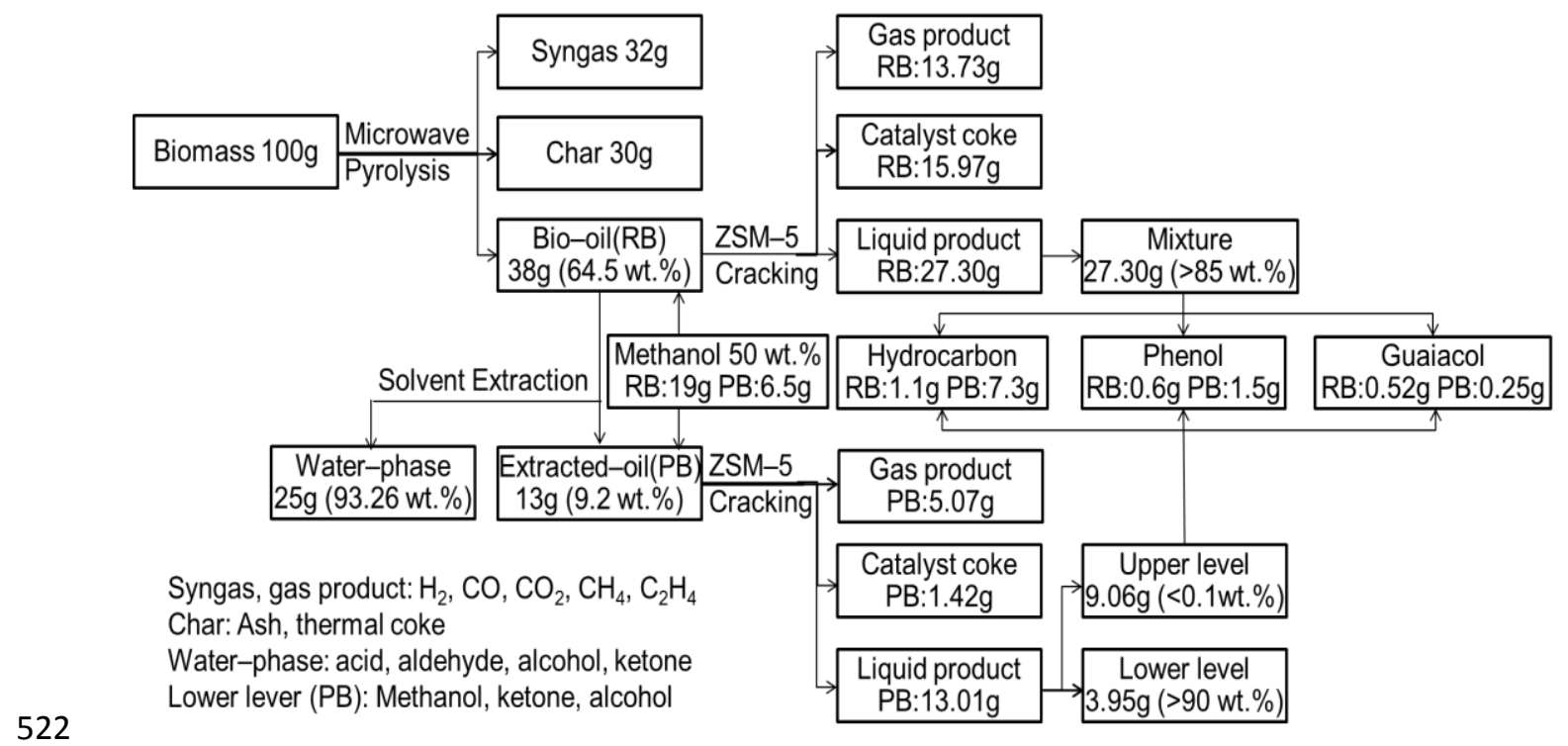

